ScIDice

\section{International Journal of Dentistry and Oral Science (IJDOS) ISSN: 2377-8075}

\title{
Frequency Of Hypodontia In Mandibular Teeth
}

Research Article

Kalaivani Natarajan ${ }^{1}$, Nivethigaa B ${ }^{2 *}$, Mahesh Ramakrishnan ${ }^{3}$

${ }^{1}$ Saveetha Dental College and Hospital, Saveetha Institute of Medical and Technical Sciences, Saveetha University, 162, Poonamallee High Road, Chennai-600077, Tamil Nadu, India.

${ }^{2}$ Senior Lecturer, Department of Orthodontics, Saveetha Dental College and Hospital, Saveetha Institute of Medical and Technical Sciences, Saveetha University 162, Poonamallee High Road, Chennai-600077, Tamil Nadu, India.

${ }^{3}$ Reader, Department of Pedodontics, Saveetha Dental College and Hospital, Saveetha Institute of Medical and Technical Sciences, Saveetha University 162, Poonamallee High Road, Chennai-600077, Tamil Nadu, India.

\section{Abstract}

Hypodontia is the term used to describe the absence of one or more teeth excluding the third molars. Commonly occurs in mandibular second premolar and maxillary lateral incisors. Prevalence of hypodontia may detrimentally affect the aesthetics and function. Hypodontia most of the time may be an indication of the existence of a need for orthodontic treatment. The aim of this study was to assess the frequency of hypodontia. The study was conducted as a retrospective, university based study. 41,000 case sheets of patients who reported from June 2019 to December 2019 were evaluated. Details of patients diagnosed with hypodontia were categorised. Among patients with hypodontia, based on the etiology of missing teeth, further sorting was done to segregate only congenitally missing teeth in the mandibular arch. The parameters tabulated include age, gender and missing teeth. Data was entered in Microsoft Excel sheet, results were obtained by statistical analysis using SPSS software v20. In our study, the frequency rate of hypodontia was higher in females $(57 \%)$ than in males $(42.8 \%)$. The mandibular anteriors are the most common congenitally missing teeth with $46.9 \%$ frequency rate.

Keywords: Hypodontia; Congenitally Missing; Mandibular Hypodontia.

\section{Introduction}

Hypodontia is the most prevalent dentofacial malformation in humans [13]. This condition refers to the developmental failure of 6 or fewer teeth [16]. It may occur as a part of a recognised genetic syndrome or as non syndromic isolated trait [2]. It'sphenotypical presentation is varied in terms of severity and as a result, various terms have been used to describe it. The terms used are congenitally missing teeth, tooth agenesis, hypodontia, oligodontia and anodontia [14]. Tooth agenesis refers to the developmental failure of a tooth, whereas other terms such as hypodontia are used for classifying the type of tooth agenesis. Oligodontia and Anodontia are used to describe more severe forms of tooth agenesis, typically absence of more than 6 teeth, anodontia means absence of the entire dentition $[3,15,18]$.

The prevalence of hypodontia, which may be increasing in time ranges from $1.6 \%$ to $36.5 \%$. Mandibular second premolars and the maxillary lateral incisors are the most commonly missing teeth [13].

Tooth agenesis is often nonsyndromic, but it can be often associated with clefts and other syndromes. Hypodontia is one of the characteristic features of certain syndromes like down's syndrome and ectodermal dysplasia. In these syndromes, there is a characteristic pattern of agenesis that is usually different from the overall population [19].

Prevalence of hypodontia may detrimentally affect the aesthetics and function. Hypodontia, most of the time maybe an indication for the existence of a need for an orthodontic treatment. Therefore, investigating the frequency of hypodontia is of significant clinical value in terms of diagnosis and treatment planning. This would be essential in preventing complications including maloc-

*Corresponding Author:

Nivethigaa B,

Senior Lecturer, Department of Orthodontics, Saveetha Dental College and Hospital, Saveetha Institute of Medical and Technical Sciences, Saveetha University 162, Poonamallee High Road, Chennai-600077, Tamil Nadu, India.

Tel: 9524234613

E-mail: Nivethigaab.sdc@saveetha.com

Received: September 06, 2020

Accepted: September 29, 2020

Published: September 30, 2020

Citation: Kalaivani Natarajan, Nivethigaa B, Mahesh Ramakrishnan. Frequency Of Hypodontia In Mandibular Teeth. Int J Dentistry Oral Sci. 2020;S1:02:009:45-47. doi: http://dx.doi.org/10.19070/2377-8075-SI02-01009

Copyright: Nivethigaa $\mathbf{B} 2020$. This is an open-access article distributed under the terms of the Creative Commons Attribution License, which permits unrestricted use, distribution and reproduction in any medium, provided the original author and source are credited. 
clusion, periodontal damage and lack of alveolar growth [13].

Previously our team has conducted numerous studies which include in vitro studies [11], review, case report [6], survey and clinical trial $[4,5,7,10,12,17,21,23-27]$. Now we are focusing on retrospective study, hence the present study was conducted to assess the frequency of hypodontia.

\section{Materials and Methods}

\section{Study setting}

This was a retrospective, University based Study. The patients who were diagnosed with hypodontia were included in the study. The study duration was from June 2019 to December 2019.

\section{Sampling}

41,000 case sheets of patients who reported from June 2019 to December 2019 were evaluated. Details of patients diagnosed with hypodontia were categorised. Among patients with hypodontia, based on the etiology of missing teeth, further sorting was done to segregate only congenitally missing teeth in the mandibular arch. The parameters tabulated include age, gender and missing teeth. The data were cross verified by another reviewer to minimise bias.

\section{Data collection and Tabulation:}

Data collected was tabulated in Microsoft Excel sheet.

\section{Statistical analysis}

The Excel sheet was transferred to the host computer and processed in SPSS. Chi square test was done to analyse the gender distribution of hypodontia in mandibular teeth.

\section{Results and Discussion}

Overall, of the 41,000 samples examined only $49(0.1 \%)$ patients had congenital missing of teeth. Figure 1 represents the frequency of hypodontia. Among those with congenital hypodontia, the frequency of hypodontia was higher in mandibular anterior teeth [23] followed by maxillary anteriors (maxillary lateral incisors -19) and mandibular posteriors (mandibular premolars - 3) Figure 2 represents the gender distribution of hypodontia, the frequency of hypodontia was higher in females $(57.1 \%)$ than in males $(42.8$ $\%)$.

Both environmental and genetic factors attributed to the occurrence of hypodontia. These include infection, trauma and medicines as well as genes that are associated with certain syndrome.

Figure 1. Shows the frequency of hypodontia of each tooth. $\mathrm{X}$ axis represents the tooth and $\mathrm{Y}$ axis represents the number of patients with congenitally missing teeth;both maxillary and mandibular anteriors (purple), both maxillary and mandibular posteriors (grey), mandibular anteriors (grey), mandibular posteriors (blue), maxillary anteriors (yellow). The frequency of hypodontia is more common in the mandibular anteriors, followed by maxillary anteriors.

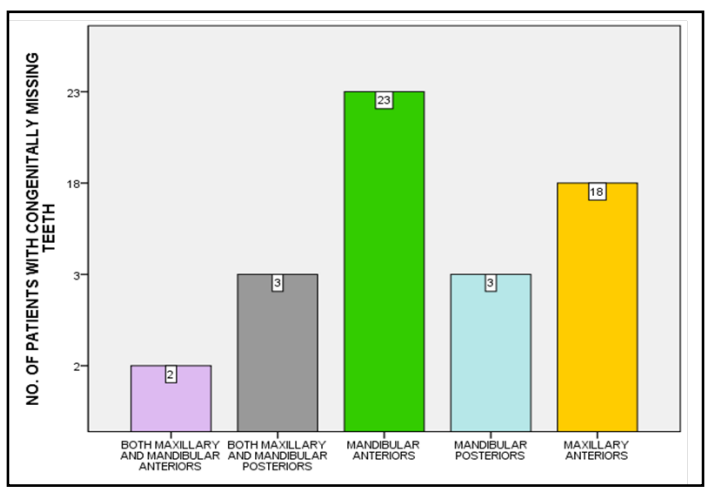

Figure 2. Shows the association of gender distribution with the frequency of hypodontia. $\mathbf{X}$ axis represents the missing tooth and $\mathrm{Y}$ axis represents the number of patients with congenitally missing teeth;female patients(blue) and male patients(red). Association tested by Chi square test $p$ value $0=0.168(>0.05)$ Statistically not significant; though females have higher frequency of hypodontia than males.

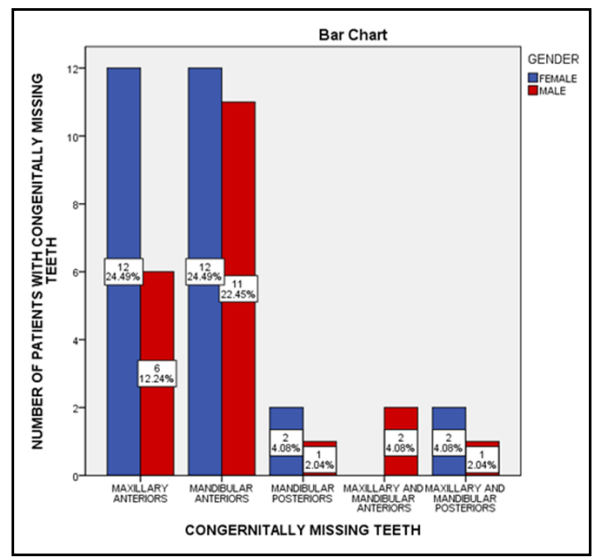


Considering the high frequencies of hypodontia and its serious esthetical, physiological, functional and even emotional complication, it's early diagnosis is necessary for enabling dentist to plan alternative preventive, multidisciplinary treatment modalities [28]. Several studies conducted earlier show that the maxillary lateral incisors and second premolars are the most common congenitally missing teeth. Previous study conducted by Vahid Rakshhan et_al states that the maxillary lateral incisors are the most frequent congenitally missing teeth [20]. Another study conducted by Renato et_al states that the mandibular premolars have the highest frequency [22]. A study conducted by BernaGokkaya et al states that the observation should be done from 10 to 15 years of age or during the regular dental visit. This is missed out in certain cases, where the diagnosis is done in later age due to improper scheduling of dental visits [9].

The association of hypodontia with gender is shown in figure 2 . The frequency of hypodontia is more common in females with $57.1 \%$ frequency rate than in males with $42.8 \%$ frequency rate. A study conducted by AzzaHussam et al [1] states that the prevalence of hypodontia is 1.4 times greater in males than in females which is a contradiction to our present study. However, another study conducted by Berna et al states, there is no significant difference in hypodontia between males and females.

Limitations of the study include Small sample size that cannot be generalized to a larger population. Possible manual errors that can occur during data collection. Further studies can be done in various places and etiology and treatment options can be analysed. The overall consensus of the present study adds up to the previous similar studies.

\section{Conclusion}

Our study claimed hypodontia or oligodontia to be more common among females than males and mandibular anteriors to be the teeth found missing most followed by Maxillary anteriors. Further analysis of a larger population is needed to make a decision regarding the prevalence of hypodontia.

\section{References}

[1]. Al-Ani AH, Antoun JS, Thomson WM, Merriman TR, Farella M. Hypodontia: An Update on Its Etiology, Classification, and Clinical Management. Biomed Res Int. 2017;2017:9378325. Pubmed PMID: 28401166.

[2]. Cobourne MT, Sharpe PT. Diseases of the tooth: the genetic and molecular basis of inherited anomalies affecting the dentition. Wiley Interdiscip Rev Dev Biol. 2013 Mar-Apr;2(2):183-212. PubmedPMID: 24009033.

[3]. Cobourne MT. Familial human hypodontia--is it all in the genes? Br Dent J. 2007 Aug 25;203(4):203-8. PubmedPMID: 17721480.

[4]. Dinesh SP, Arun AV, Sundari KK, Samantha C, Ambika K. An indigenously designed apparatus for measuring orthodontic force. J ClinDiagn Res. 2013 Nov;7(11):2623-6. PubmedPMID: 24392423.

[5]. Felicita AS, Chandrasekar S, Shanthasundari KK. Determination of craniofacial relation among the subethnic Indian population: a modified approach - (Sagittal relation). Indian J Dent Res. 2012 May-Jun;23(3):305-12. PubmedPMID: 23059564

[6]. Felicita AS. Orthodontic management of a dilacerated central incisor and partially impacted canine with unilateral extraction - A case report. Saudi Dent J. 2017 Oct;29(4):185-193. PubmedPMID: 29033530.
[7]. Felicita AS. Quantification of intrusive/retraction force and moment generated during en-masse retraction of maxillary anterior teeth using mini-implants: A conceptual approach. Dental Press J Orthod. 2017 SepOct:22(5):47-55. PubmedPMID: 29160344.

[8]. Felicita AS. Orthodontic extrusion of Ellis Class VIII fracture of maxillary lateral incisor - The sling shot method. Saudi Dent J. 2018 Jul;30(3):265269. PubmedPMID: 29942113.

[9]. okkaya B, Kargul B. Prevalence and Pattern of Non-SyndromicHypodontia in a Group of Turkish Children. ActaStomatol Croat. 2016 Mar;50(1):5864. PubmedPMID: 27688427

[10]. Jain RK, Kumar SP, Manjula WS. Comparison of intrusion effects on maxillary incisors among mini implant anchorage, j-hook headgear and utility arch. J ClinDiagn Res. 2014 Jul;8(7):ZC21-4. PubmedPMID: 25177631.

[11]. Kamisetty SK, Verma JK, Arun, Sundari S, Chandrasekhar S, Kumar A. SBS vsInhouse Recycling Methods-An Invitro Evaluation. J ClinDiagn Res. 2015 Sep;9(9):ZC04-8. PubmedPMID: 26501002.

[12]. Krishnan S, Pandian S, Kumar S A. Effect of bisphosphonates on orthodontic tooth movement-an update. J ClinDiagn Res. 2015 Apr;9(4):ZE01-5. PubmedPMID: 26023659.

[13]. Matalova E, Fleischmannova J, Sharpe PT, Tucker AS. Tooth agenesis: from molecular genetics to molecular dentistry. J Dent Res. 2008 Jul;87(7):61723. PubmedPMID: 18573979.

[14]. Nieminen P. Genetic basis of tooth agenesis. J ExpZool B MolDevEvol. 2009 Jun 15;312B(4):320-42. PubmedPMID: 19219933.

[15]. Nikopensius T, Annilo T, Jagomägi T, Gilissen C, Kals M, Krjutškov K, Mägi R, Eelmets M, Gerst-Talas U, Remm M, Saag M, Hoischen A, Metspalu A. Non-syndromic tooth agenesis associated with a nonsense mutation in ectodysplasin-A (EDA). J Dent Res. 2013 Jun;92(6):507-11. PubmedPMID: 23603338.

[16]. Nunn JH, Carter NE, Gillgrass TJ, Hobson RS, Jepson NJ, Meechan JG, Nohl FS. The interdisciplinary management of hypodontia: background and role of paediatric dentistry. Br Dent J. 2003 Mar 8;194(5):245-51. PubmedPMID: 12658298.

[17]. Pandian KS, Krishnan S, Kumar SA. Angular photogrammetric analysis of the soft-tissue facial profile of Indian adults. Indian J Dent Res. 2018 MarApr;29(2):137-143.PubmedPMID: 29652003.

[18]. Parkin N, Elcock C, Smith RN, Griffin RC, Brook AH. The aetiology of hypodontia: the prevalence, severity and location of hypodontia within families. Arch Oral Biol. 2009 Dec;54Suppl 1:S52-6. PubmedPMID: 19100963.

[19]. Polder BJ, Van't Hof MA, Van der Linden FP, Kuijpers-Jagtman AM. A meta-analysis of the prevalence of dental agenesis of permanent teeth. Community Dent Oral Epidemiol. 2004 Jun;32(3):217-26. PubmedPMID: 15151692.

[20]. Rakhshan V. Congenitally missing teeth (hypodontia): A review of the literature concerning the etiology, prevalence, risk factors, patterns and treatment. Dent Res J (Isfahan). 2015 Jan-Feb;12(1):1-13. Pubmed PMID: 25709668.

[21]. Ramesh Kumar KR, ShantaSundari KK, Venkatesan A, Chandrasekar S. Depth of resin penetration into enamel with 3 types of enamel conditioning methods: a confocal microscopic study. Am J OrthodDentofacialOrthop. 2011 Oct;140(4):479-85. PubmedPMID: 21967934.

[22]. Rédua RB, Rédua PCB. Hypodontia of mandibular incisors: considerations on the orthodontic treatment. Dental Press J Orthod. 2018 Aug 1;23(4):7987. PubmedPMID: 30304157

[23]. Rubika J, SumathiFelicita A, Sivambiga V. Gonial angle as an indicator for the prediction of growth pattern. World Journal of Dentistry. 2015;6(3):161-3.

[24]. Samantha C, Sundari S, Chandrasekhar S, Sivamurty G, Dinesh S. Comparative Evaluation of Two Bis-GMA Based Orthodontic Bonding Adhesives - A Randomized Clinical Trial. J ClinDiagn Res. 2017 Apr;11(4):ZC40ZC44. PubmedPMID: 28571259.

[25]. Sivamurthy G, Sundari S. Stress distribution patterns at mini-implant site during retraction and intrusion--a three-dimensional finite element study. ProgOrthod. 2016;17:4. PubmedPMID: 26780464.

[26]. Vikram NR, Prabhakar R, Kumar SA, Karthikeyan MK, Saravanan R. Ball Headed Mini Implant. J ClinDiagn Res. 2017 Jan;1 1(1):ZL02-ZL03. PubmedPMID: 28274084.

[27]. Viswanath A, Ramamurthy J, Dinesh SP, Srinivas A. Obstructive sleep apnea: awakening the hidden truth. Niger J ClinPract. 2015 Jan-Feb;18(1):1-7. PubmedPMID: 25511335.

[28]. Wu CC, Wong RW, Hagg EU. A review of hypodontia: the possible etiologies and orthodontic, surgical and restorative treatment options: Conventional and futuristic. Hong Kong Dental Journal. 2007. 